\title{
A simple way for the electropolymerization of porphyrins
}

\author{
Alain Giraudeau ${ }^{\mathrm{a}, *}$, Delphine Schaming ${ }^{\mathrm{b}}$, Jian Hao ${ }^{\mathrm{b}}$, Rana Farha ${ }^{\mathrm{c}, \mathrm{d}}$, Michel Goldmann ${ }^{\mathrm{c}, \mathrm{e}}$, \\ Laurent Ruhlmann ${ }^{\mathrm{b}, *}$
}

a Laboratoire d'Electrochimie et de Chimie-Physique du Corps Solide, UMR 7177 CNRS/Université de Strasbourg, 4 rue Blaise Pascal, 67070 Strasbourg Cedex, France

${ }^{\mathrm{b}}$ Laboratoire de Chimie Physique, UMR 8000 CNRS/Université Paris-Sud 11, Faculté des Sciences d'Orsay, Bâtiment 349,91405 Orsay Cedex, France

${ }^{\mathrm{c}}$ Institut des NanoSciences de Paris, UMR 7588 CNRS/Université Paris 6, 140 rue de Lourmel, 75015 Paris, France

${ }^{\mathrm{d}}$ Laboratoire d'Analyse de Contrôle des Systèmes Complexes, Ecole Centrale d'Electronique, 37 quai de Grenelle, 75015 Paris, France

${ }^{\mathrm{e}}$ Université Paris Descartes, 45 rue des Saint Pères, 75006 Paris, France

A novel and simple method for the electropolymerization of porphyrins is developed. Polarization of a working electrode at the second ring-oxidation potential of octaethylporphyrins in the presence of appropriate bridging nucleophiles is sufficient to realize the coating of the electrode by a cationic polymeric film. Characterizations of the obtained films are presented.

\section{Introduction}

Porphyrins have found various important applications, in particular as photosensitizer and/or catalysts in chemical and photochemical reactions [1,2]. Numerous methods for porphyrins immobilization on solid supports have been reported. Electrodes coated with electroactive porphyrins provided avenues for fundamental studies as well as developments in the practical uses of the deposited materials.

The first strategy to polymerize porphyrins was the use of bridging ligands to produce coordination polymers or oligomers $[\mathrm{MPorph}(\mathrm{Nu}-\mathrm{Nu})]_{n}(\mathrm{M}=\mathrm{Fe}, \mathrm{Ru}, \mathrm{Os} ; \mathrm{Nu}-\mathrm{Nu}=$ pyrazine, 4,4'-bipyridine, 1,4-diazabicyclo[2,2,2]octane, 4,4'-azopyridine) as illustrated in the top of Fig. $1[3,4]$. In this case, the metalloporphyrins react with a variety of bridging ligands $\mathrm{Nu}-\mathrm{Nu}$ to produce insoluble powders leaving the solution virtually colorless.

The other most common strategy in porphyrins polymerization, which was widely developed since the studies of Macor and Spiro [5], consists in the oxidative radical coupling of the porphyrins via

* Corresponding authors. Tel.: +33 1691544 38; fax: +33 169156188 (L. Ruhlmann); tel.: +33 3902414 16; fax: +33 390241431 (A. Giraudeau).

E-mail addresses: giraudeau@urs.u-strasbg.fr (A. Giraudeau), laurent.ruhlmann@ lcp.u-psud.fr (L. Ruhlmann). substituents on the ring periphery [6-8]. Thus the starting porphyrin subunit should bear oxidizable substituents. The scanning of the potential to the oxidation potential of the substituents generates the corresponding radicals, which in turn initiate further polymerization of the porphyrin. In some situations a direct ring coupling was performed [9].

Besides the radical coupling process, previous works [10-12] initiated another route in the porphyrins building block conception using the strategy of nucleophilic attack onto porphyrins cation radicals. This process of nucleophilic attack was recently applied to the electrosynthesis of a porphyrinate-viologen wire and cationic copolymers using porphyrins bearing an appropriate base of Lewis as substituent [13-15].

Although the electropolymerization appeared to be an easy process in the coating of solid materials with porphyrinic films, a primary step was generally required. This step consisted in the synthesis of the starting monomeric subunit (target porphyrin) bearing appropriate substituents whose electrochemical or chemical reactivity would be the key step for the subsequent polymerizations. Many synthetic difficulties must be overcome to achieve this goal.

To our knowledge, no general processes of coating electrodes with porphyrins exist that allow anodic oxidative electropolymerization in the absence of a key (electro)active substituent on the 


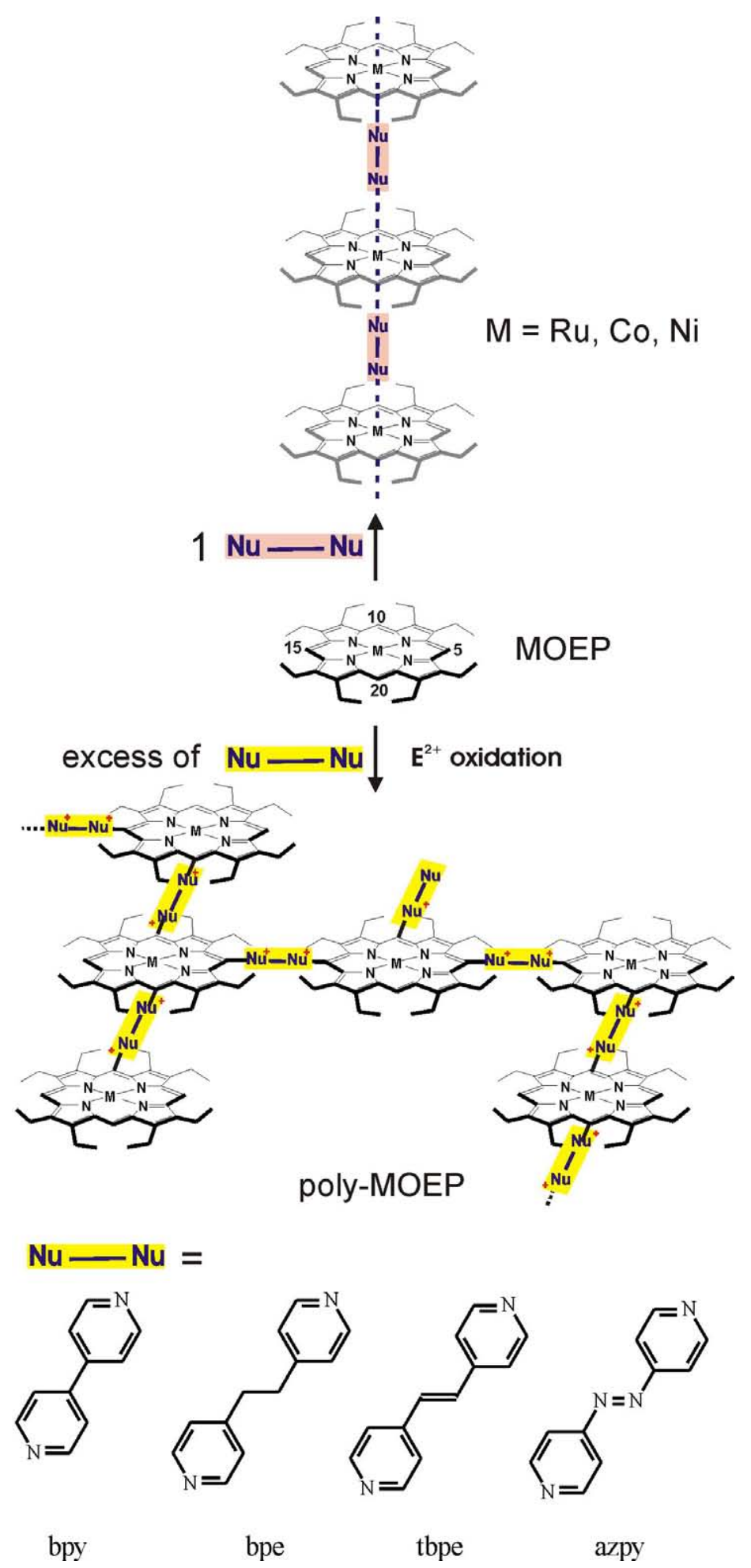

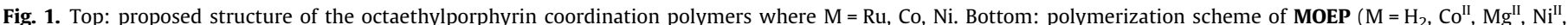

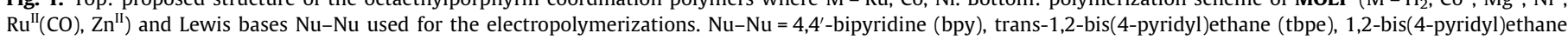
(bpe), 4,4'-azopyridine (azpy). For clarification, the coordination of $\mathrm{Nu}-\mathrm{Nu}$ has been omitted.

porphyrin ring. In this context we report hereafter a simple and efficient method to electropolymerize unmodified porphyrins, i.e. without the preliminary attachment of specific substituents on the porphyrin ring. Within these lines, the formation of copolymers poly-MOEP from MOEP $\left(\mathrm{M}=\mathrm{H}_{2}, \mathrm{Co}^{\mathrm{II}}, \mathrm{Mg}^{\mathrm{II}}, \mathrm{Ni}^{\mathrm{II}}, \mathrm{Ru}^{\mathrm{II}}(\mathrm{CO}), \mathrm{Zn}^{\mathrm{II}}\right)$ is described (Fig. 1, bottom).

\section{Results and discussion}

Recently, we reported the formation of copolymers from monomers bearing respectively one bipyridinium (zinc-5-bipyridiniumoctaethyl-porphyrinate) or two bipyridinium units in positions 5 and 10 (zinc-5,10-dibipyridinium-octaethyl-porphyrinate) [14]. 
Such studies involved a coupling process which necessitated the preliminary synthesis of a starting porphyrin bearing appropriate nucleophiles as substituents.

\subsection{Synthesis of copolymers poly-MOEP}

In this work, a general process of coating electrodes with MOEP porphyrins ( $\left.\mathrm{M}=\mathrm{H}_{2}, \mathrm{Co}^{\mathrm{II}}, \mathrm{Mg}^{\mathrm{II}}, \mathrm{Ni}^{\mathrm{II}}, \mathrm{Ru}^{\mathrm{II}}(\mathrm{CO}), \mathrm{Zn}^{\mathrm{II}}\right)$ allowing anodic oxidative electropolymerization in the absence of a key (electro)active substituent on the porphyrin ring is described. This process is based on the following principle: Polarization of a working electrode at the porphyrin's second ring-oxidation potential in the presence of an appropriate bridging nucleophile in the bulk of the electrolytic solution is sufficient for a one pot electropolymerization of the target porphyrin (Fig. 1, bottom).

We illustrate here and discuss the use of this method for the polymerization of six commercial octaethylporphyrins (MOEP) where $\mathrm{M}=\mathrm{H}_{2}, \mathrm{Co}^{\mathrm{II}}, \mathrm{Mg}^{\mathrm{II}}, \mathrm{Ni}^{\mathrm{II}}, \mathrm{Ru}^{\mathrm{II}}(\mathrm{CO}), \mathrm{Zn}^{\mathrm{II}}$. These porphyrins were chosen both for their various nature and redox behavior to validate the presented process. For $\mathrm{Zn}, \mathrm{Mg}$ and $\mathrm{Ru}(\mathrm{CO})$ porphyrins, two ring oxidation steps generated - as for the free base - the corresponding dications with an unreacted central metal. Co and Ni porphyrins are known to be ring oxidized with, in addition, central metal oxidation [16]. Moreover, $\mathrm{Ni}$, Co and Ru porphyrins are potentially good catalysts [2,17], free base could be thought to incorporate metals [18].

The bridging nucleophile, 4,4'-bipyridine (bpy), was chosen because of recent studies concerning its use in the electrochemical assemblies of porphyrins [11] and the numerous data on the reduction of the viologen and bipyridinium groups [13-15,19]. Other Lewis bases behaving conjugated or non conjugated pyridine rings were also used as spacers.

We used an excess of the bridging ligand $(4 \mathrm{mM})$ in the presence of metalloporphyrins $(0.25 \mathrm{mM})$ in order to prevent the formation of the ligand-bridged metalloporphyrin polymers $[\operatorname{MOEP}(\mathrm{Nu}-\mathrm{Nu})]_{n}(\mathrm{M}=\mathrm{Ru}, \mathrm{Co}, \mathrm{Ni})$ and to favor in solution monometallic complexes of the type $[\mathrm{MOEP}(\mathrm{Nu}-\mathrm{Nu})]_{2}$ which does not bother the electropolymerization $[3,4]$.

The oxidation potentials of the studied porphyrins are listed in Table 1 . They are in agreement with the literature data [16]. After addition of the bpy ( $4 \mathrm{mM})$ the anodic scan showed the successive one-electron oxidation peaks of the porphyrins followed by the oxidation signal of chemically generated isoporphyrins $[16,20]$. All of these oxidation signals progressively shifted anodically as the coating of the electrode progressed. That was already observed with zinc-5-bipyridinium-octaethyl-porphyrinate and zinc-5,10dibipyridinium-octaethyl-porphyrinate. For all of the studied porphyrins, the CV's evolution indicated that polymerization took place at the surface of the electrode. Fig. 2A illustrates this evolution in the case of the Mg porphyrin.

Upon the repetitive cathodic scans, three one electron reduction peaks were observed at ca. $0.21 \mathrm{~V},-0.19 \mathrm{~V}$ and $-0.49 \mathrm{~V} v s$. SCE which corresponded respectively to the typical electronic transfers onto the viologen linkers and bipyridinium substituents as already discussed $[10,11,19]$. The increase of the height of these typical signals was taken as an indication of the regular growth of the polymeric films on the working electrode [21]. When the potential scans were reversed before the second ring oxidation step, no polymerization occurred.

After 25 scans the electrodes were removed from the electrochemical cell, washed with $\mathrm{CH}_{3} \mathrm{CN}$ and used as working electrode in a new electrolytic solution with only the solvent and the supporting electrolyte. An example of a recorded voltammogram is illustrated in Fig. 2B. After one hundred iterative scans the corresponding CVs remained quasi unchanged suggesting the good stability of these films.
Table 1

Electrochemical data for MOEP and copolymers poly-MOEP $\left(\mathrm{M}=\mathrm{H}_{2}, \mathrm{Co}^{\mathrm{II}}, \mathrm{Mg}^{\mathrm{II}}, \mathrm{Ni}^{\mathrm{II}}\right.$, $\left.\mathrm{Ru}^{\mathrm{II}}(\mathrm{CO}), \mathrm{Zn}^{\mathrm{II}}\right)$ obtained from bpy and copolymers poly-ZnOEP obtained from bpe, tbpe and azpy.

\begin{tabular}{|c|c|c|c|c|c|c|}
\hline \multirow[t]{2}{*}{ Porphyrins } & \multicolumn{3}{|c|}{ Oxidation } & \multicolumn{3}{|c|}{ Reduction } \\
\hline & $E_{3}$ & $E_{2}$ & $E_{1}$ & \multicolumn{3}{|c|}{$\mathrm{V}^{2+}$ or $\mathrm{bpy}^{+}$} \\
\hline $\mathrm{H}_{2} \mathrm{OEP}^{\mathrm{a}}$ & & 1.15 & 0.80 & & & \\
\hline CoOEP & 1.31 & 0.95 & $0.70^{\mathrm{e}}$ & & & \\
\hline $\mathrm{MgOEP}^{\mathrm{a}}$ & & 0.82 & 0.55 & & & \\
\hline NiOEPa & $>1.60^{\mathrm{e}}$ & 1.25 & 0.75 & & & \\
\hline $\mathrm{Ru}(\mathrm{CO}) \mathrm{OEP} \mathrm{P}^{\mathrm{a}}$ & & 1.11 & 0.70 & & & \\
\hline $\mathrm{ZnOEP}{ }^{\mathrm{a}}$ & & 0.96 & 0.68 & & & \\
\hline Poly- $\mathrm{H}_{2} \mathrm{OEP}^{\mathrm{b}}$ & & & $1.01^{\mathrm{irr}, \mathrm{c}}$ & $0.03^{d}$ & -0.26 & -0.53 \\
\hline Poly-CoOEP ${ }^{\mathrm{b}}$ & & & $1.20^{\mathrm{irr}, \mathrm{c}}$ & 0.20 & -0.25 & -0.53 \\
\hline Poly-MgOEP & & & $1.55^{\mathrm{irr}, \mathrm{c}}$ & 0.21 & -0.19 & -0.49 \\
\hline Poly-NiOEP ${ }^{\mathrm{b}}$ & & & $1.28^{\mathrm{irr}, \mathrm{c}}$ & -0.02 & -0.30 & -0.50 \\
\hline Poly-Ru(CO)OEP & & & & 0.10 & -0.35 & -0.50 \\
\hline Poly-ZnOEP ${ }^{\mathrm{b}}$ & & & & 0.02 & -0.26 & -0.58 \\
\hline Poly-ZnOEP-bpe ${ }^{\mathrm{b}}$ & & & & bpe $^{2+}$ & & bpe $^{+}$ \\
\hline Poly-ZnOEP-tbpe & & & $1.68^{\mathrm{irr}, \mathrm{c}}$ & $\begin{array}{l}-0.44 \\
\text { tbpe }^{2+}\end{array}$ & & $\begin{array}{l}-0.78 \\
\text { tbpe }^{+}\end{array}$ \\
\hline & & & $1.69^{\mathrm{irr}, \mathrm{c}}$ & -0.27 & & -0.52 \\
\hline Poly-ZnOEP-azpy ${ }^{\mathrm{b}}$ & & & & azpy $^{2+}$ & & azpy $^{+}$ \\
\hline & & & $1.56^{\mathrm{irr}, \mathrm{c}}$ & 0.10 & & $-0.84^{\mathrm{irr}}$ \\
\hline
\end{tabular}

All potentials in $\mathrm{V} v s$. SCE were obtained from cyclic voltammetry in $1,2-\mathrm{C}_{2} \mathrm{H}_{4} \mathrm{Cl}_{2}$ containing $0.1 \mathrm{M}\left(\mathrm{NEt}_{4}\right) \mathrm{PF}_{6}$. Scan rate $=0.2 \mathrm{~V} \mathrm{~s}^{-1}$.

a Working electrode: Pt electrode.

b Working electrode ITO, $S=1 \mathrm{~cm}^{2}$ after 25 scans.

c Peak potential, $E_{\mathrm{pa}}$.

d Observed only on the reverse scan.

e Oxidation of the metal.

The key step of the presented electropolymerization approach of octaethylporphyrins should be attributed to the chemical reactivity of the methine bridges of the octaethylporphyrins which allowed rapid formation of isoporphyrins when the dications were in the presence of nucleophilic species [10,11,20,22-25].

If the nucleophile presented two accessible basic sites, a coupling of the oxidized porphyrins could occur and then iterative cyclic scans would develop film's growth. Because the four methine positions of the MOEP are free, the nucleophilic attack could occur statistically at $5,10,15$ and 20 positions. The polymers obtained are also oxidizable and one to four bipyridines may therefore be added to the porphyrin ring. As a result, various polymeric forms of the porphyrins linked by viologen groups would be obtained with, in addition, porphyrin units bearing bipyridinium substituents at their periphery (Fig. 1).

A typical UV-vis spectrum recorded on a coated ITO electrode is depicted in Fig. 2C. The shape of all of the different UV-vis spectra revealed identical characteristics, and consisted in a large absorption band whose maximum was red shifted compared to the monomer. This evolution could be interpreted by the exciton-coupling theory involving intra- and inter-molecular excitonic interactions between the porphyrins subunits [26-33]. The red-shift of the soret (B) band compared to the corresponding unsubstituted porphyrins resulted from the electron-withdrawing effects $[34,35]$ of the meso-substituent bipyridinium and/or viologen on the porphyrin. In the scanning atomic force micrographs recorded on the coated surface of ITO electrodes, the copolymers polyMOEP appeared in the form of tightly packed coils with a diameter of ca. 30-40 nm (Fig. 2D) as already depicted [15].

\subsection{Synthesis of copolymers poly-ZnOEP-bpe, poly-ZnOEP-tbpe and poly-ZnOEP-azpy}

The polymerizations of the porphyrins in the presence of $4,4^{\prime}$ bipyridine could be extended to other spacers by varying the nat- 

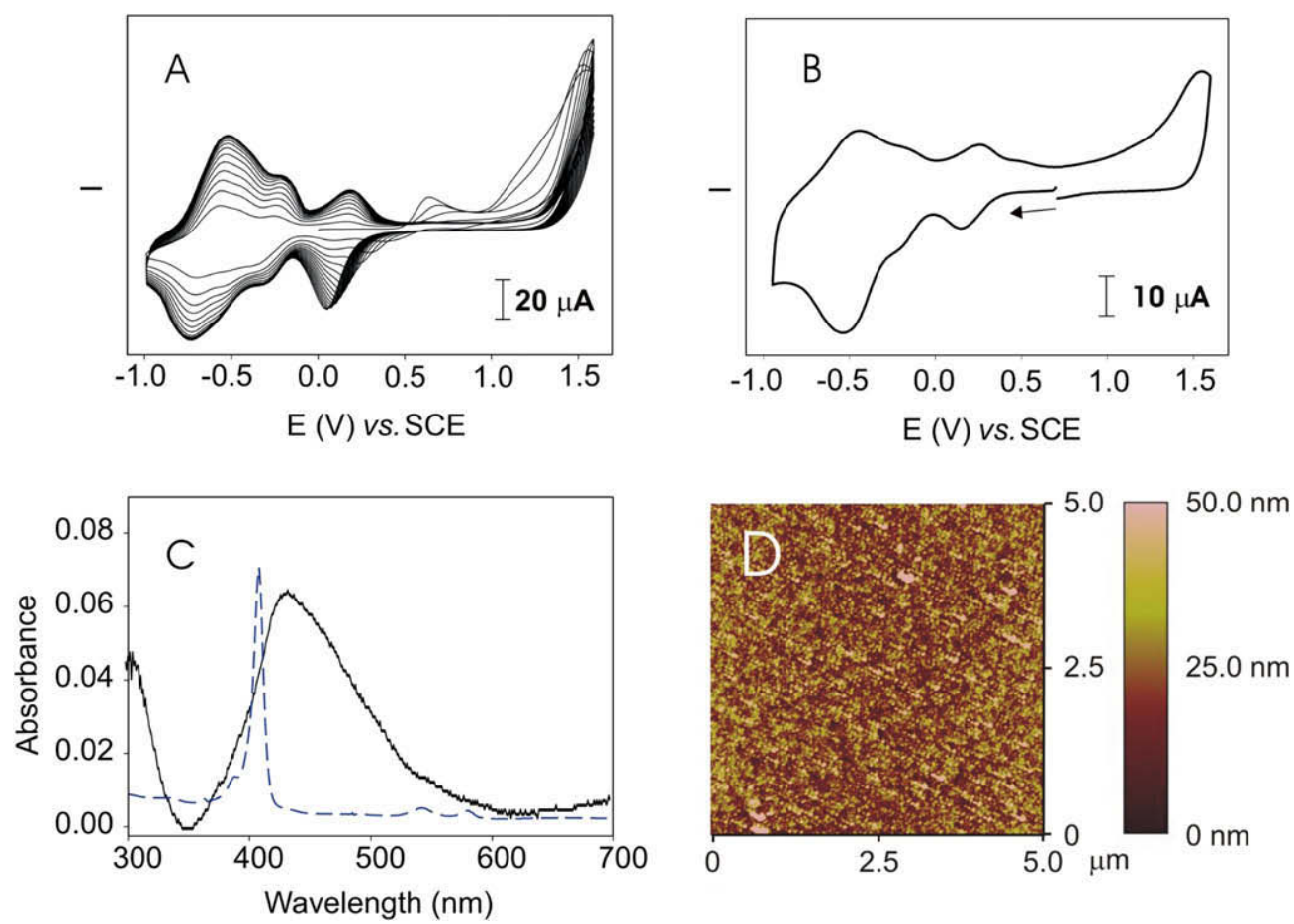

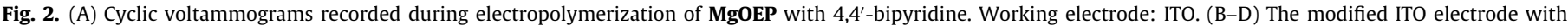

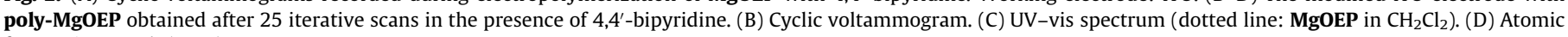
force micrograph (AFM).

ure of Nu-Nu. 1,2-Bis(4-pyridyl)ethane (bpe), trans-1,2-bis(4-pyridyl)ethene (tbpe) and 4,4'-azopyridine (azpy) were used with success instead of 4,4'-bipyridine (bpy).

As discussed for 4,4'-bipyridine the new peaks observed in reduction by cyclic voltammetry for each new spacer indicated that an insoluble species which had deposited on the electrode was undergoing reversible redox processes (Fig. 3A and B). A film on the electrode could be observed after several scans. This film must be electroconductive as indicated by the steady growth of the recorded peaks. After rinsing the working electrode, the new voltammograms carried out in an electrolytic solution with only the solvent and the supporting electrolyte did not change during the scans indicating that the polymers were stable against oxidation and reduction. Redox characteristics of the films obtained with ZnOEP were given in Table 1. The UV-visible spectra and the scanning atomic force micrographs of the films deposited on ITO glass electrodes were similar to those observed with bpy (Fig. 3C).

\subsection{Discussion of electropolymerization}

The main goal of this work was to propose and validate a novel strategy for the electropolymerization of porphyrins. The presented polymerizations which allowed to obtain stable conductive films were carried out in the same experimental conditions but each one of the porphyrins has specific characteristics. Also it would be difficult to discuss their impact on the morphology of the films. That could be only the purpose of particular studies as already done [13-15]. Nevertheless qualitative observations could be reported. The polymers obtained were coils. If we accept that the absorbance of the UV-vis spectra of the different porphyrinic films correlated with their respective thickness, the thinner films were obtained with the free base, the nickel and cobalt moieties. These porphyrins were oxidized at the higher potentials.

The reported process of easy polymerization of porphyrins (EPOP process) can be depicted with the following scheme:

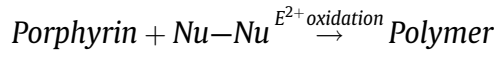

$\mathrm{E}^{2+}$ corresponded to the potential of the second ring oxidation of the porphyrin. $\mathrm{Nu}-\mathrm{Nu}$ was the appropriate bridging nucleophile. The polymerization required generation of the porphyrin dications [36].

The chemical reactivity of the $\pi$-cation radicals and dications of porphyrins has been already discussed by numerous authors [22-25]. Also it was demonstrated that porphyrins could be linked by electrochemical processes taking advantage of the reactivity of their $\pi$-cation radicals. In the presence of appropriate Lewis bases, the electrochemical oxidation of porphyrins allowed to carry out substitution(s) on beta and/or meso positions $[10,11]$. This property has been used to build various modular assemblies of porphyrins [12] from the corresponding $\pi$-cation radicals.

In the present work we made advantage of the reactivity of the dications to form polymers. Even the process seems similar, this second approach which require the generation of dications is not a generalization of the first concept (reactivity of the $\pi$-cation radicals) and the observed results from monocations did not allow any anticipation of the fate of the dications.

Indeed the nucleophilic attack kinetic on the $\pi$-radical cations was slow, and therefore the possible reaction of substitution did not occur at the electrode surface but in the bulk of the solution. One of the consequences was that the obtained products were electrolysis conditions dependent, like for example, the degree of substitution of the porphyrins which was function of the applied electrolysis potential [11-15].

In contrast the polymerizations described here imply a fast kinetic attack of the Lewis bases onto the generated dications. The dications of the porphyrins are known to induce fast nucleophilic reactions in the presence of appropriate Lewis bases [20,22,23]. This reactivity allows here to realize a simultaneous coupling of the oxidized porphyrins leading to a polymerization at the surface of the working electrodes. Furthermore these kinetic factors rule 

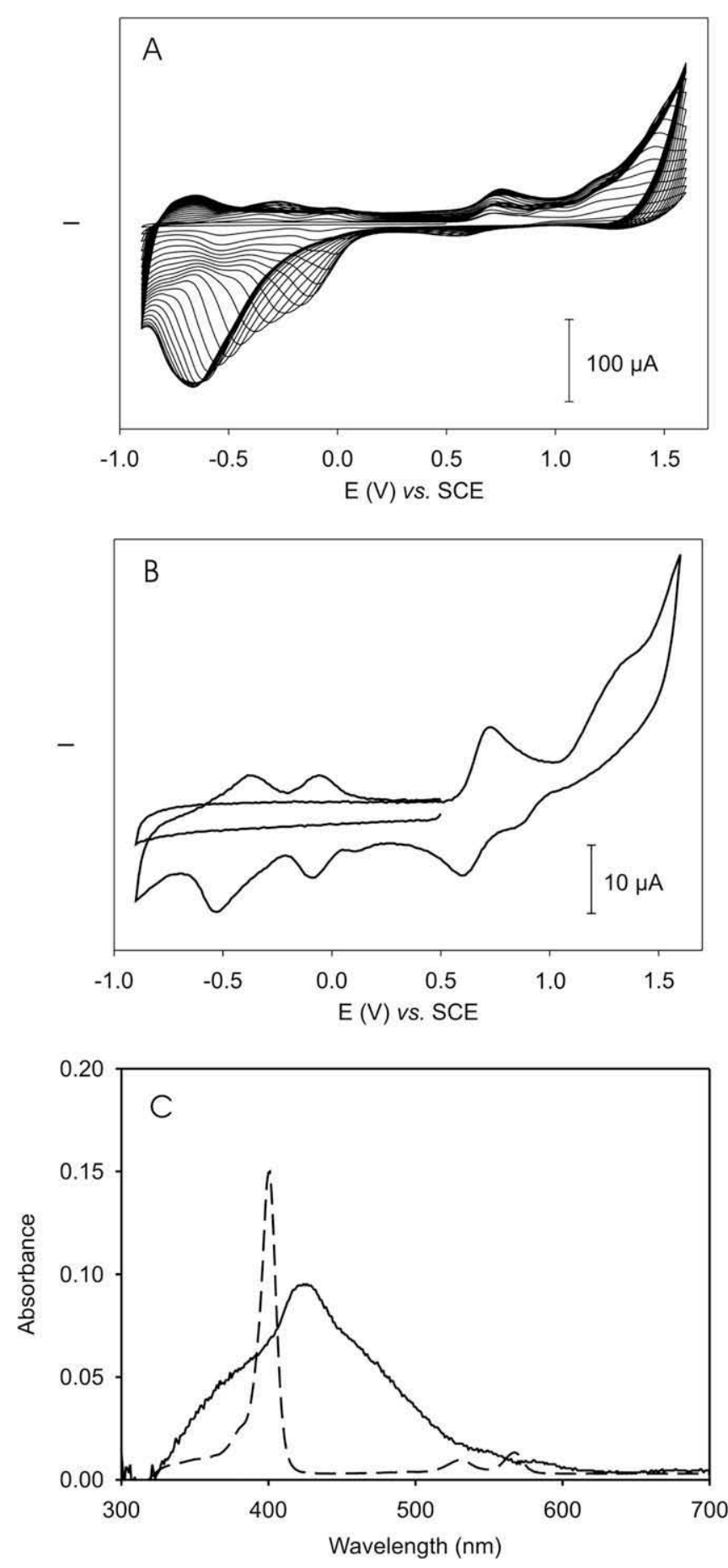

Fig. 3. (A) Cyclic voltammograms recorded during electropolymerization of ZnOEP with tbpe. Working electrode: ITO. (B) The first scan recorded during electropolymerization. (C) UV-vis spectra; dotted line: ZnOEP in $\mathrm{CH}_{2} \mathrm{Cl}_{2}$; full line: polyZnOEP-tbpe.

out the way of an initial coupling of the $\pi$-cation radicals which would be oxidized later to form the polymers.

Elsewhere polymerizations have been already discussed using porphyrins bearing bipyridinium units as substituents [13-15]. Well oriented copolymers coated at the surface of electrodes and their compact aggregation in regular 3D substructures of "peanuts" were observed. Even similar, it is not trivial that both approaches may be considered as the same.
On the first look both approaches are comparable, both using nucleophilic attacks. The new path discussed here, however is quite different, since the first preparing step can be omitted and the porphyrins do not need any specific functionalization. Moreover the presented polymerizations would imply only oxidized porphyrins which should react quasi simultaneously to realize the linkage between the molecules. That is mainly due to the particular fate of OEP's dications whose two meso positions can react quasi simultaneously [22-25,37,38]. This chemical reactivity was previously illustrated, in particular with the nitration of octaethylporphyrins [38]. That would explain also the lack of polymerization with the TPP series in these conditions. In this case, a beta-beta coupling between the porphyrin moities should be realized. This type of linkage, involving a nucleophilic attack at the beta positions, is probably kinetically much more slower than the above reaction of coupling at the meso positions. That is the consequence of a complex chemical process and was presented initially by Dolphin et al. [23]. They discussed the reaction of pyridine onto the dication $\mathrm{ZnTPP}^{2+}$, demonstrating that the primary nucleophilic attack occurred at the meso site before activation of the beta position. Mechanistic investigations on these reactions of polymerization are under way.

Finally the clear characterization of the various polymers obtained in similar conditions, as well as the good solubility of previously described porphyrin assemblies, like the pentameric species [39], allowed us to exclude a precipitation of aggregates on the electrode surface.

\section{Conclusion}

In summary, we have developed a novel and simple method for the electropolymerization of porphyrins in comparison of the already known approaches. The presented results provide clear cut experimental evidence that the dications of octaethylporphyrins are able to produce stable conducting polymers. A Lewis base containing at least two distinct nucleophilic sites was considered as a potential linker for the assumption that each of its nucleophilic sites might react with the methine bridges. Specific porphyrin functionalizations that would provide potentially promising properties could be present if two methine bridges remained accessible for the anodic linkage reaction.

The synthetic method reported is the first to allow an electropolymerization of porphyrins with the simplest experimental process. It does not necessitate the preliminary synthesis of a substituted porphyrin bearing the reactive bridging group. This alternative strategy to the usual radical coupling method opens an efficient new way to create various materials through appropriate selection of both the porphyrins and Lewis bases used as bridging spacers.

\section{Experimental}

\subsection{Materials}

All solvents, MOEP $\left(\mathrm{M}=\mathrm{H}_{2}, \mathrm{Co}^{\mathrm{II}}, \mathrm{Mg}^{\mathrm{II}}, \mathrm{Ni}^{\mathrm{II}}, \mathrm{Ru}^{\mathrm{II}}(\mathrm{CO}), \mathrm{Zn}^{\mathrm{II}}\right)$ were of reagent grade quality and used without further purification. The ligands 4,4'-bipyridine (bpy), trans-1,2-bis(4-pyridyl)ethane (tbpe), 1,2-bis(4-pyridyl)ethane (bpe), 4,4'-azopyridine (azpy) were used without purification (Sigma-Aldrich products).

\subsection{Electrochemistry}

All electrochemical measurements were carried out under argon at $20^{\circ} \mathrm{C}$ on a platinum electrode $(d=1 \mathrm{~mm})$ or a glassy carbon disk electrode $(d=3 \mathrm{~mm})$. One side indium-tin-oxide (ITO)-coated 
electrode with a surface of about $1 \mathrm{~cm}^{2}$ were also used (Delta Technology Limited, $100 \Omega / \square$ ).

Voltammetric data were obtained with a standard three-electrodes system using a PARSTAT 2273 potentiostat. ITO electrodes served as optically transparent electrodes to record UV-visible spectra of the deposited copolymers. A platinum wire was used as auxiliary electrode. The reference electrode was a saturated calomel electrode (SCE). It was electrically connected to the solution by a junction bridge filled with the corresponding solvent containing the supporting electrolyte.

Potential values in oxidation are measured on the first scan, because of the further polymerizations of the porphyrins.

\subsection{Copolymers poly-MOEP, poly-ZnOEP-bpe, poly-ZnOEP-tbpe and poly-ZnOEP-azpy}

Electropolymerizations were carried out under an argon atmosphere in $0.1 \mathrm{M}$ solutions of tetraethylammonium hexafluorophosphate in $1,2-\mathrm{C}_{2} \mathrm{H}_{4} \mathrm{Cl}_{2}$ and containing $0.25 \mathrm{mM}$ of $\operatorname{MOEP}\left(\mathrm{M}=\mathrm{H}_{2}\right.$, $\left.\mathrm{Co}^{\mathrm{II}}, \mathrm{Mg}^{\mathrm{II}}, \mathrm{Ni}^{\mathrm{II}}, \mathrm{Ru}^{\mathrm{II}}(\mathrm{CO}), \mathrm{Zn}^{\mathrm{II}}\right)$ and $4 \mathrm{mM}$ of bridging nucleophile $\mathrm{Nu}-\mathrm{Nu}$. Cyclic scanning $\left(0.2 \mathrm{~V} \mathrm{~s}^{-1}\right)$ of the working electrode was applied at potentials between -0.90 and $1.60 \mathrm{~V}$ vs. SCE, and the solution was continuously maintained under argon. The starting potential of the first scan as well as the ending potential value of the final scan were $0.6 \mathrm{~V}$. Thus at the end of the electropolymerization, the porphyrin subunits (MOEP) of the copolymers were not oxidized (neutral form). After electrolysis, the working electrode was washed five times with $10 \mathrm{~mL}$ of $\mathrm{CH}_{3} \mathrm{CN}$ to remove traces of the conducting salt present on the deposited film and was finally dried under argon at room temperature.

In the case of poly-ZnOEP-azpy, due to reduction of azpy at $-0.89 \mathrm{~V}$ and $-1.25 \mathrm{~V}$, cyclic scanning of the working electrode was applied at potential between 0 and $1.60 \mathrm{~V} v$ s. SCE.

\subsection{Spectroscopy}

UV-vis spectra were recorded on a Perkin Elmer Lamda 9 spectrophotometer. Glass plates covered with indium-tin-oxide (ITO) were used to obtain UV-vis spectra of the electrochemically deposited copolymers.

\subsection{Atomic force microscopy (AFM)}

AFM was performed directly on the surface of the ITO electrode using a Nanoscope III (Digital Instruments, Santa Barbara, CA) in the tapping mode under ambient conditions. Silicon cantilevers (Nanosensors, Wetzlar/Germany) with a spring constant between 31 and $77 \mathrm{~N} / \mathrm{m}$ and a resonance frequency in the range of 299$402 \mathrm{kHz}$ were used. The scanning rate was $1.0 \mathrm{~Hz}$.

\section{Acknowledgments}

This work was supported by the CNRS, the Université Paris-Sud (11) (Orsay, France) and the Université de Strasbourg (France). This work was also supported by the ANR agency, project No. JC05_52437, NCPPOM.

\section{Appendix A. Supplementary material}

AFM, UV-visible spectra, and cyclic voltammograms of the modified ITO electrode with poly-MOEP $\left(\mathrm{M}=\mathrm{H}_{2}, \mathrm{Co}^{\mathrm{II}}, \mathrm{Mg}^{\mathrm{II}}, \mathrm{Ni}^{\mathrm{II}}\right.$, $\mathrm{Ru}^{\mathrm{II}}(\mathrm{CO}), \mathrm{Zn}^{\mathrm{II}}$ ) with $\mathrm{Nu}-\mathrm{Nu}=4,4^{\prime}$-bipyridine (bpy) and of $\mathrm{ZnOEP}$ with 1,2-bis(4-pyridyl)ethane (bpe), trans-1,2-bis(4-pyridyl)ethene (tbpe) and 4,4'-azopyridine (azpy). Supplementary data associated with this article can be found, in the online version, at doi:10.1016/j.jelechem.2009.10.018.

\section{References}

[1] D. Gust, T.A. Moore, A.L. Moore, Acc. Chem. Res. 34 (2001) 40-48.

[2] J.R. Lindsay Smith, in: R.A. Shelson (Ed.), Metalloporphyrins in Catalytic Oxidation, Marcel Dekker, New York, 1994.

[3] J.P. Collman, J.T. McDevitt, C.R. Leidner, G.T. Yee, J.B. Torrance, W.A. Little, J. Am. Chem. Soc. 109 (1987) 4606-4614.

[4] V. Marvaud, J.P. Launay, Inorg. Chem. 32 (1993) 1376-1382.

[5] K.A. Macor, T.G. Spiro, J. Am. Chem. Soc. 105 (1983) 5601-5607.

[6] A. Bettelheim, B.A. White, S.A. Raybuck, R.W. Murray, Inorg. Chem. 26 (1987) 1009-1017.

[7] C. Paul-Roth, J. Rault-Berthelot, G. Simonneaux, J. Letessier, J.F. Bergamini, J. Electroanal. Chem. 606 (2007) 103-116.

[8] J. Rault-Berthelot, C. Paul-Roth, C. Poriel, S. Juillard, S. Ballut, S. Drouet, G. Simonneaux, J. Electroanal. Chem. 623 (2008) 204-214.

[9] T. Ogawa, Y. Nishimoto, N. Yoshida, N. Ono, A. Osuka, Angew. Chem., Int. Ed. 38 (1999) 176-179.

[10] L. El Kahef, M. Gross, A. Giraudeau, J. Chem. Soc. Chem. Commun. (1989) 963.

[11] A. Giraudeau, L. Ruhlmann, L. El Kahef, M. Gross, J. Am. Chem. Soc. 118 (1996) 2969-2979.

[12] L. Ruhlmann, A. Giraudeau, Eur. J. Inorg. Chem. (2001) 659-668.

[13] L. Ruhlmann, A. Schulz, A. Giraudeau, C. Messerschmidt, J.-H. Fuhrhop, J. Am. Chem. Soc. 121 (1999) 6664-6667.

[14] J. Hao, A. Giraudeau, Z. Ping, L. Ruhlmann, Langmuir 24 (2008) 1600-1603.

[15] L. Ruhlmann, J. Hao, Z. Ping, A. Giraudeau, J. Electroanal. Chem. 621 (2008) 2230.

[16] K.M. Kadish, K.M. Smith, R. Guilard (Eds.), The Porphyrin Handbook, vols. 8-9, Academic Press, San Diego, CA, 2000.

[17] K.C. Cheung, W.L. Wong, D.L. Ma, T.S. Lai, K.Y. Wong, Coord. Chem. Rev. 251 (2007) 2367-2385.

[18] T. Malinski, A. Ciszewski, J.R. Fish, Anal. Chem. 62 (1990) 909-914.

[19] G.S. Würm, H. Berneth, Top. Curr. Chem. 92 (1980) 1-44.

[20] A.S. Hinman, B.J. Pavelich, A.E. Kondo, S. Pons, J. Electroanal. Chem. 234 (1987) $145-162$.

[21] A.J. Bard, Adv. Phys. Org. Chem. 13 (1976) 155-278.

[22] D. Dolphin, Z. Muljiani, K. Rousseau, D.C. Borg, J. Fajer, R.H. Felton, N.Y. Ann, Acad. Sci. 206 (1973) 117-119.

[23] D. Dolphin, D.J. Halko, E.C. Johnson, K. Rousseau, In: Porphyrins Chemistry Advances, Ann Arbor Science, MI, 1979 (Chapter 10).

[24] G.H. Barnett, M.F. Hudson, S.W. Mc Combie, K.M. Smith, J. Chem. Soc., Perkin Trans. I (1973) 691-694.

[25] K. Rachlewicz, L. Latos-Grazynski, Inorg. Chem. 34 (1995) 718-727.

[26] M. Kasha, Rev. Mod. Phys. 31 (1959) 162-169.

[27] J.L. Sessler, V.L. Capuano, A. Harriman, J. Am. Chem. Soc. 115 (1993) 46184628.

[28] A. Osuka, Y. Ikawa, K. Maruyama, Bull. Chem. Soc. Jpn. 65 (1992) 3322-3330.

[29] R.W. Wagner, J.S. Lindsey, J. Am. Chem. Soc. 116 (1994) 9759-9760.

[30] J. Seth, V. Palaniappan, T.E. Johnson, S. Prathapan, J.S. Lindsey, D.F. Bocian, J. Am. Chem. Soc. 116 (1994) 10578-10592.

[31] J.L. Sessler, M.R. Johnson, S.E. Creager, J.C. Fettinger, J.A. Ibers, J. Am. Chem. Soc. 112 (1990) 9310-9329.

[32] M. El Baraka, J.M. Jannot, L. Ruhlmann, A. Giraudeau, M. Deunié, P. Seta, Photochem. Photobio. A: Chem. 113 (1998) 163-169.

[33] L. Ruhlmann, M. Gross, A. Giraudeau, Chem. Eur. J. 9 (2003) 5085-5096.

[34] J. Hirota, I. Okura, J. Phys. Chem. 97 (1993) 6867-6870.

[35] A. Giraudeau, H.J. Callot, J. Jordan, I. Ezahr, M. Gross, J. Am. Chem. Soc. 101 (1979) 3857-3862.

[36] The polymerization at $\mathrm{E}^{2+}$ of NiOEP might imply that $\mathrm{Ni}^{\mathrm{III}}$ would be generated from the dication $\mathrm{Ni}^{\mathrm{II}} \mathrm{OEP}^{2+}$ as discussed by: K.M. Kadish, E. Van Caemelbecke, P. Boulas, F. D'Souza, E. Vogel, M. Kisters, C.J. Medforth, K.M. Smith, Inorg. Chem. 32 (1993) 4177-4178.

[37] W.A. Lee, T.C. Bruice, Inorg. Chem. 25 (1986) 131-135.

[38] R. Bonnett, G.F. Stephenson, J. Org. Chem. 30 (1965) 2791-2798.

[39] L. Ruhlmann, S. Lobstein, M. Gross, A. Giraudeau, J. Org. Chem. 64 (1999) 13521355. 